\title{
Pyruvate dehydrogenase phosphatase deficiency
}

INSERM

\section{Source}

INSERM. (1999). Orphanet: an online rare disease and orphan drug data base. Pyruvate dehydrogenase phosphatase deficiency. ORPHA:79246

Pyruvate dehydrogenase phosphatase deficiency is a very rare subtype of pyruvate dehydrogenase deficiency (PDHD, see this term) characterized by lactic acidemia in the neonatal period. 